\title{
Red cell distribution width as a predictor of severity and outcome of acute organophosphorus poisoned cases admitted to Poison Control Center Ain Shams University Hospitals (A prospective study)
}

\author{
Ehdaa A. Mahmoud, Manal A. Abdel Salam, Heba M. Halawa, Rabab Nabil Hafez ${ }^{1}$,
}

${ }^{1}$ Department of Forensic Medicine and Clinical Toxicology, Faculty of Medicine-Ain Shams University, Cairo Egypt.

\begin{abstract}
Background: Organophosphates are highly toxic compounds for human beings. Organophosphate compounds (OPCs) poisoning by unintentional or suicidal ingestion is associated with high morbidity and mortality, particularly in developing countries. Aim of the study: Assessing the prognostic value of red cell distribution width (RDW) and white blood cells (WBCs), hemoglobin and platelet count on severity and outcome in patients with acute organophosphate poisoning in conjunction with clinical signs using the Peradeniya Organophosphorus Poisoning (POP) score. This is in addition to evaluation and comparison between RDW with pseudo choline esterase (PChE) level as early OPCs poisoning predictor. Methods: A prospective cross-sectional study was done on 100 acutely OPCs intoxicated patients admitted to Poison Control Center Ain Shams University Hospitals (PCC-ASUHs) from June 2019 till December 2019. All cases were clinically evaluated. RDW was done on admission and after 24 hours while WBCs, hemoglobin, platelets, PChE level and arterial blood gases (ABG) were estimated immediately after admission prior to treatment. Results: High RDW values indicated poor prognosis. There was a highly significant correlation between RDW values and the need for mechanical ventilation (MV). There was a significant correlation between high WBCs count, severity of OPCs poisoning and the need for MV. Lower mean $\mathrm{pH}$, higher mean $\mathrm{PCO}_{2}$, lower mean $\mathrm{HCO}_{3}$, lower mean PChE levels, and higher mean WBCs count were noted in patients on MV compared to patients without MV. Conclusion: RDW values on admission can be a reliable predictor of severity and outcome in contrast to PChE levels which showed nonsignificant correlation with severity. Additionally, there was a significant correlation between WBCs with the need of MV. RDW on admission can predict the need for mechanical ventilation with sensitivity $(58.97 \%)$, specificity $(83.61 \%)$ at cutoff value more than 14.4 . RDW on admission had a sensitivity of $75 \%$ and specificity of $73.75 \%$ with a cut-off value of 14.3 in predicting mortality in patients with OPCs poisoning. Recommendations: RDW is a simple parameter that could be used in assessing the prognosis of acute organophosphorus poisoning. WBCs count could also be used in those patients to predict the need of MV.
\end{abstract}

Key words Red cell distribution width, acute organophosphate poisoning.

\section{Introduction}

A

grochemicals, including pesticides and fertilizers, are used broadly in agriculture to kill pests that harm crops and enhance productivity. These chemicals are potentially toxic to some organisms including humans and need to be safely used and properly disposed (Cestonaro et al., 2020).

The major classes of pesticides are insecticides, herbicides, fungicides, rodenticides and fumigants. They are responsible for most of acute poisoning patients presenting to emergency departments. Organophosphates are effective insecticides that have been extensively used in agriculture for more than 50 years (King and Aaron, 2015).

Peradeniya Organophosphorus poisoning (POP) scale could be a simple and effective score system to determine the early need for ventilation. This scale uses
6 clinical parameters including (miosis, fasciculations, respiration, bradycardia, and level of consciousness) to assess the severity of poisoning (Vernekar and Shivaraj, 2017; Chaudhary and Kalmegh, 2018).

It is important to identify new prognostic markers for the management of patients with pesticide poisoning in emergency settings. Red cell distribution width (RDW) is a quantitative method of the size variability of the red blood cells (RBCs). It is used during differential diagnosis of types of anemia and measured in complete blood count (CBC). The mechanism of elevated RDW is suggested to be oxidative stress and systemic inflammation. Additionally, it was found that inflammatory cytokines suppress bone marrow maturation of RBCs releasing them to the blood immature which cause increase in RDW (Kang et al., 2014; Dündar et al., 2015). 
It was found that one of the commonest laboratory findings in patients with organophosphates poisoning is the elevation of leukocytic count which is not only elevated on admission, but it also had prognostic value for mortality (Sapkota et al., 2018).

\section{Aim of the Study}

I. Investigate and assess the prognostic value of red cell distribution width (RDW) and (WBCs, hemoglobin, and platelets) measured on admission to the emergency department on severity and outcome in patients with acute organophosphate poisoning in conjunction with clinical signs using the Peradeniya Organophosphorus Poisoning (POP) score.

II. Compare between RDW with pseudo choline esterase as early OPCs poisoning predictor in patients admitted to the Poison Control Center - Ain Shams university Hospitals (PCC-ASUHs).

\section{Patients and Methods}

A prospective cross sectional, hospital-based study was carried out on 100 acute organophosphorus poisoning patients admitted to PCC-ASUHs within the period from June 2019 till December 2019. Diagnosis was based on history of OPCs exposure with identification of a clinical picture suggestive of OPCs poisoning (Peter et al., 2014).

Exclusion criteria included ages under 16 years old, receiving pre-hospital treatment, co-ingestion of other agents, prehospital cardiac arrest, discharge against medical advice, and coexisting hematological diseases, cancer, or trauma.

Clinical variables were employed in the calculation of Peradeniya Organophosphorus poisoning (POP) scale including (miosis, fasciculations, respiration, bradycardia, and level of consciousness) (Vernekar and Shivaraj, 2017).

According to POP score patients were classified into two subgroups: mechanically ventilated and nonventilated group. The differences in the (RDW, WBCs, hemoglobin, platelets, $\mathrm{ABG}\left(\mathrm{pH}, \mathrm{PCO}_{2}\right.$ and $\left.\mathrm{HCO}_{3}\right)$ and Pseudocholinesterase enzyme) between the groups was compared.

\section{Laboratory data:}

Blood samples were collected on admission after initial stabilization and the following investigations were done: Arterial blood gases $(\mathrm{pH}$, $\mathrm{PaCO}_{2}$ and $\mathrm{HCO}_{3}$ ), complete blood count including (RDW, WBCs, hemoglobin, and platelets) and serum PChE level. RDW was also repeated after 24 hours.

Management and hospital disposition was done according to the patient's condition and according to the protocol of management in PCC-ASUHs. Outcome were either complete recovery, recovery with complications or death.

\section{Ethical consideration:}

An informed consent was taken from the patients or their legal relatives before inclusion in the study. Approval of Research Ethics Committee of Faculty of Medicine Ain Shams University and the Head of PCC-ASUHs was obtained. Data were collected with consideration of confidentiality issues.

\section{Statistical analysis:}

The obtained data were revised, coded, and organized for statistical analysis using SPSS (Statistical package for Social Science) version (20) software (SPSS Inc, USA). Data were presented and suitable analysis was done according to the type of data obtained for each parameter. Continuous data were expressed as mean $\pm \mathrm{SD}$ and as a percentage for categorical variables.

\section{Results}

Patients' age ranged between 16 and 64 years with mean \pm SD $(27.060 \pm 12.521)$. Delay time between exposure and seeking medical advice ranged between 0.5 and 24 hours with mean \pm SD $(5.050 \pm 5.683)$ hours. Table (1) shows ranges and mean values of recorded vital data, POP score and recorded laboratory investigations. Regarding mechanical ventilation, it was needed in $(39 \%)$ of patients.

Regarding RDW, normal RDW was recorded in $54 \%$ of patients and who had high RDW after 24 hours were $46 \%$ with no significant difference between RDW level recorded on admission and after 24 hours (Tables $2,3)$. However, there is a significant correlation between RDW values and the need for $\mathrm{MV}$ on admission $(\mathrm{P}=0.001)$ and after 24 hours $(\mathrm{P}=<0.001)$ (Tables 4$)$.

On correlation of RDW on admission and after 24 hours with age, vital data, POP score, laboratory parameters, positive correlation with POP score with highly significant result $(\mathrm{p}<0.01)$ was noted. RDW level also shows a significant correlation after 24 hours with high WBCs count $(\mathrm{P}=0.033)$, systolic blood pressure $(\mathrm{P}=0.053)$, diastolic blood pressure $(\mathrm{P}=.0 .038)$, $\mathrm{pH}(\mathrm{P}=0.018), \mathrm{PCO}_{2}(\mathrm{P}=0.002), \mathrm{HCO}_{3}(\mathrm{P}=0.008)$ On the other hand, RDW shows a non-significant correlation with PChE, age, delay time, pulse, platelets, and hemoglobin (Table 5).

RDW on admission can predict need for mechanical ventilation with sensitivity (58.97\%), specificity $(83.61 \%)$ at cutoff point more than 14.4 . However, RDW after 24 hours can predict need for mechanical ventilation with sensitivity (61.54\%), specificity $(86.89 \%)$ at cutoff value more than 14.7 (Table 6) \& (figure 1\&2).

Additionally, RDW on admission had a sensitivity of $75 \%$ and specificity of $73.75 \%$ with a cut-off value of 14.3 in predicting mortality in patients with OPCs poisoning. However, after 24 hours RDW had a sensitivity of $75 \%$ and the specificity of $73.75 \%$ with a cut-off value of 14.3 in predicting mortality (Table 7) \& (figure $3 \& 4$ )

About $80 \%$ of all the studied patients recovered (71\% recovered without complications and 9\% after occurrence of complications as ventilation acquired pneumonia (VAP) or shock). On the other hand, 20\% of the studied patients died $(13 \%$ due to intermediate syndrome, $4 \%$ with shock and $3 \%$ complicated with VAP) (Table 8).

Regarding the need for mechanical ventilation (M.V) in the studied groups, results of ABG showed lower mean $\mathrm{pH}$ in patients on M.V than patients without M.V. In addition, mean $\mathrm{PCO}_{2}$ in patients on $\mathrm{M} . \mathrm{V}$ was higher than patients without M.V. Mean $\mathrm{HCO}_{3}$ in 
patients on M.V was lower than patients without M.V. Mean PChE was lower in patients on M.V, than patients without M.V. Additionally, there is no significant correlation between pseudocholinesterase $(\mathrm{P}=0.736)$ and the need for mechanical ventilation (Table 9).

Additionally, there was a significant correlation between WBCs with the need of M.V. Mean WBCs in patients on mechanical ventilation was higher than that in patients without M.V. While there was no significant correlation between hemoglobin and platelets with the need of M.V (Table10).

Table (1): Ranges and mean values of recorded age, delay time, vital data, POP score and recorded laboratory investigations in studied patients.

\begin{tabular}{|c|c|c|}
\hline & Range & Mean \pm SD \\
\hline Age (Years) & $16-64$ & $27.060 \pm 12.521$ \\
\hline Delay (Hours) & $0.5-24$ & $5.050 \pm 5.683$ \\
\hline Pulse (Beat/min) & $40-130$ & $82.091 \pm 17.713$ \\
\hline Mean blood pressure & $60-143.3$ & $84.944 \pm 14.085$ \\
\hline POP score & $3-9$ & $60-143.3$ \\
\hline PH & $7.13-7.54$ & $7.321 \pm 0.100$ \\
\hline PCO2(mmHg) & $23-75$ & $47.290 \pm 10.315$ \\
\hline HCO3 (meq/L) & $10-36$ & $20.534 \pm 3.805$ \\
\hline PChE(U/L) & $200-3000$ & $1127.670 \pm 655.790$ \\
\hline WBCs (103/mm3) & & $12.725 \pm 4.994$ \\
\hline Platelets (103/mm3) & & $342.080 \pm 81.954$ \\
\hline Hb (g/d) & & $12.539 \pm 1.611$ \\
\hline
\end{tabular}

PChE: pseudocholinesterase enzyme, SD: standard deviation, WBCs: white blood cells, Hb: hemoglobin, n: number,

SD: standard deviation

Table (2): RDW at admission and after 24 hours in studied patients.

\begin{tabular}{|c|c|c|c|}
\hline & & Number & Percentage \\
\hline \multirow{2}{*}{ RDW on admission } & Normal & 55 & $55 \%$ \\
\hline & High & 45 & $45 \%$ \\
\hline \multirow{2}{*}{ RDW after 24 hours } & Normal & 54 & $54 \%$ \\
\hline & High & 46 & $46 \%$ \\
\hline
\end{tabular}

RDW: red cell distribution width

Table (3): Independent t-test analysis of RDW at admission and after 24 hours in studied patients.

\begin{tabular}{|c|c|c|c|c|c|c|}
\hline \multirow{2}{*}{ RDW } & \multicolumn{2}{|c|}{ Time } & \multicolumn{2}{c|}{ Differences } & \multicolumn{2}{c|}{ Paired Test } \\
\cline { 2 - 6 } & On admission & After 24 Hours & Mean & SD & T & P-value \\
\hline Range & $11.5-18.9$ & $11.5-21.5$ & \multirow{2}{*}{0.169} & 0.972 & -1.738 & 0.085 \\
\hline Mean \pm SD & $13.965 \pm 1.253$ & $14.134 \pm 1.543$ & & \\
\hline
\end{tabular}

RDW: red cell distribution width, SD: standard deviation, $P>0.05$ : non-significant, $\square: P<0.05$ : significant,

$\square \square: P<0.01$ : highly significant,

Table (4): Independent t- test statistical analysis of RDW level on admission and after 24 hours with need of mechanical ventilation in studied patients.

\begin{tabular}{|c|c|c|c|c|c|}
\hline \multirow{2}{*}{\multicolumn{2}{|c|}{ RDW }} & \multicolumn{2}{|c|}{ M.V } & \multicolumn{2}{|c|}{ t-test } \\
\hline & & \multirow{2}{*}{$\begin{array}{c}\text { Yes } \\
11.6-18.9\end{array}$} & \multirow{2}{*}{$\begin{array}{c}\text { No } \\
11.5-17.6\end{array}$} & $\mathbf{T}$ & P-value \\
\hline \multirow{2}{*}{ On admission } & Range & & & \multirow{2}{*}{3.267} & \multirow{2}{*}{$0.001 \square \square$} \\
\hline & Mean \pm SD & $14.454 \pm 1.347$ & $13.652 \pm 1.090$ & & \\
\hline \multirow{2}{*}{ After 24 Hours } & Range & $12.1-21.5$ & $11.5-17$ & \multirow{2}{*}{4.801} & \multirow{2}{*}{$<0.001 \square \square$} \\
\hline & Mean \pm SD & $14.972 \pm 1.815$ & $13.598 \pm 1.045$ & & \\
\hline Differences & Mean \pm SD & $-0.518 \pm 1.469$ & $0.054 \pm 0.249$ & & \\
\hline Paired Test & P-value & $0.034 *$ & 0.095 & & \\
\hline
\end{tabular}

RDW: red cell distribution width, SD: standard deviation, $P>0.05$ : non-significant, $\square: P<0.05$ : significant,

$\square \square: P<0.01$ : highly significant. 
Table (5): Pearson coefficient correlations between RDW on admission and after 24 hours with recorded age, delay time, vital data, POP score and recorded laboratory investigations in studied patients.

\begin{tabular}{|l|c|c|c|c|}
\hline \multirow{2}{*}{} & \multicolumn{2}{|c|}{ RDW On admission } & \multicolumn{2}{c|}{ RDW After 24 Hours } \\
\cline { 2 - 5 } & R & P-value & R & 0.188 \\
\hline Age (Years) & 0.070 & 0.486 & 0.133 & 0.550 \\
\hline Delay (Hours) & 0.013 & 0.896 & 0.061 & 0.113 \\
\hline Pulse (Beat/min) & -0.155 & 0.125 & -0.160 & $0.053^{*}$ \\
\hline SBP & -0.169 & 0.093 & -0.194 & $0.038 \square \square$ \\
\hline DBP & -0.160 & 0.111 & -0.207 & $<0.001 \square \square$ \\
\hline POP score & 0.337 & $0.001 \square \square$ & 0.402 & $0.018 \square$ \\
\hline Ph & -0.159 & 0.115 & -0.236 & $0.002 \square \square$ \\
\hline PCO2(mmHg) & 0.178 & 0.077 & 0.313 & $0.008 \square \square$ \\
\hline HCO3 (meq/L) & -0.247 & $0.013 \square$ & -0.263 & 0.215 \\
\hline PChE(U/L) & -0.112 & 0.265 & -0.125 & $0.033 \square$ \\
\hline WBCs (103/mm3) & 0.166 & 0.100 & 0.214 & 0.168 \\
\hline Platelets (103/mm3) & -0.117 & 0.245 & -0.139 & 0.437 \\
\hline Hb (g/d) & 0.002 & 0.986 & 0.079 & \\
\hline RDW: red cell distibution
\end{tabular}

RDW: red cell distribution width, PChE: pseudocholinesterase enzyme, WBCs: white blood cells, Hb: hemoglobin, SD: standard deviation, $P>0.05$ : non-significant, $\square: P<0.05$ : significant, $\square \square: P<0.01$ : highly significant, $r:$ (Pearson's Correlation Coefficient), Pearson's rvaries between +1 and $-1(+1$ is a perfect positive correlation, -1 is a perfect negative correlation. 0 means there is no linear correlation at all)

Table (6): ROC curve of RDW on admission and after 24 hour and mechanical ventilation of the studied patients.

\begin{tabular}{|c|c|c|c|c|c|c|}
\hline & Cutoff & Sensitivity & Specificity & PPV & NPV & Accuracy \\
\hline RDW on admission & $>14.4$ & 58.97 & 83.61 & 69.7 & 76.1 & $70.1 \%$ \\
\hline RDW after 24 hours & $>14.7$ & 61.54 & 86.89 & 75 & 77.9 & $76.3 \%$ \\
\hline
\end{tabular}

ROC: the receiver operating characteristic, PPV: positive predictive value, $N P V$ : negative predictive value

Table (7): ROC curve of RDW on admission and after 24 hour and mortality of the studied patients.

\begin{tabular}{|c|c|c|c|c|c|c|}
\hline & Cutoff & Sensitivity & Specificity & PPV & NPV & Accuracy \\
\hline RDW on admission & $>14.3$ & 75.00 & 73.75 & 41.7 & 92.2 & $71.3 \%$ \\
\hline RDW after 24 hours & $>14.5$ & 90.00 & 78.75 & 51.4 & 96.9 & $84.9 \%$ \\
\hline
\end{tabular}

ROC: the receiver operating characteristic, PPV: positive predictive value, NPV: negative predictive value

Table (8): Independent t- test statistical analysis of RDW on admission in relation to outcome in studied patients.

\begin{tabular}{|c|c|c|c|c|c|}
\hline \multicolumn{2}{|c|}{} & \multicolumn{2}{c|}{ RDW on admission } & \multicolumn{2}{c|}{ t-test } \\
\cline { 3 - 6 } & N & Mean \pm SD & T & \multirow{2}{*}{-2.962} & $0.004 \square \square$ \\
\cline { 2 - 5 } Outcome & Recovery & 80 & $13.786 \pm 1.149$ & $14.680 \pm 1.422$ \\
\hline
\end{tabular}

$P>0.05$ : non-significant, $\square: P<0.05$ : significant, $\square \square: P<0.01$ : highly significant, $N$ : number, SD: standard deviation

Table (9): Independent $\mathbf{t}$ test statistical analysis of patients according to need for mechanical ventilation and their laboratory investigations (ABG components (pH, PCO2 and HCO3), and PChE) in studied patients.

\begin{tabular}{|c|c|c|c|c|c|}
\hline \multirow{2}{*}{\multicolumn{2}{|c|}{ Laboratory investigations }} & \multicolumn{2}{|c|}{ MV } & \multirow{2}{*}{ Test statistic } & \multirow{2}{*}{ P-value } \\
\hline & & Yes & No & & \\
\hline \multirow{2}{*}{$\mathbf{p H}$} & Range & $7.13-7.41$ & $7.22-7.54$ & \multirow{2}{*}{-4.846} & \multirow{2}{*}{$<0.001 \square \square$} \\
\hline & Mean \pm SD & $7.267 \pm 0.070$ & $7.356 \pm 0.101$ & & \\
\hline \multirow{2}{*}{$\begin{array}{c}\mathrm{PCO}_{2} \\
(\mathrm{mmHg})\end{array}$} & Range & $28-75$ & $23-69$ & \multirow{2}{*}{2.877} & \multirow{2}{*}{$0.005 \square \square$} \\
\hline & Mean \pm SD & $50.872 \pm 12.444$ & $45.000 \pm 7.987$ & & \\
\hline \multirow{2}{*}{$\begin{array}{c}\mathrm{HCO}_{3} \\
(\mathrm{meq} / \mathrm{L})\end{array}$} & Range & $10-26$ & $16-36$ & \multirow{2}{*}{-5.368} & \multirow{2}{*}{$<0.001 \square \square$} \\
\hline & Mean \pm SD & $18.277 \pm 2.980$ & $21.977 \pm 3.583$ & & \\
\hline \multirow{2}{*}{$\begin{array}{l}\text { PchE } \\
\text { (U/L) }\end{array}$} & Range & $200-3000$ & $262-2995$ & \multirow{2}{*}{-0.339} & \multirow{2}{*}{0.736} \\
\hline & Mean \pm SD & $1099.769 \pm 711.476$ & $1145.508 \pm 623.039$ & & \\
\hline
\end{tabular}

$P>0.05:$ non-significant, $\square: P<0.05$ : significant, $\square \square: P<0.01$ : highly significant, PChE: pseudo choline esterase enzyme, SD: standard deviation, $M V$ : mechanical ventilation 
Table (10): Independent $t$ test statistical analysis of patients according to need for mechanical ventilation and their hematological investigations (WBCs, Hb and Platelets).

\begin{tabular}{|c|c|c|c|c|c|}
\hline \multirow{2}{*}{\multicolumn{2}{|c|}{ Hematological investigations }} & \multicolumn{2}{|c|}{ M.V } & \multirow{2}{*}{ Test statistic } & \multirow{2}{*}{ P-value } \\
\hline & & Yes & No & & \\
\hline \multirow{2}{*}{$\begin{array}{c}\text { WBCs } \\
\left(10^{3} / \mathbf{m m}^{3}\right)\end{array}$} & Range & $5.2-28.2$ & $5.5-23$ & \multirow{2}{*}{3.774} & \multirow{2}{*}{$<0.001 \square \square$} \\
\hline & Mean \pm SD & $14.938 \pm 5.885$ & $11.310 \pm 3.741$ & & \\
\hline \multirow{2}{*}{$\begin{array}{c}\mathbf{H b} \\
(\mathrm{g} / \mathrm{dl})\end{array}$} & Range & $10.5-19.6$ & $7.5-17.3$ & \multirow{2}{*}{1.693} & \multirow{2}{*}{0.09} \\
\hline & Mean \pm SD & $12.877 \pm 1.616$ & $12.323 \pm 1.583$ & & \\
\hline \multirow{2}{*}{$\begin{array}{c}\text { Platelets } \\
\left(10^{3} / \mathrm{mm}^{3}\right)\end{array}$} & Range & $71-585$ & $194-480$ & \multirow{2}{*}{-1.449} & \multirow{2}{*}{0.124} \\
\hline & Mean \pm SD & $327.308 \pm 96.701$ & $351.525 \pm 70.193$ & & \\
\hline
\end{tabular}

$P>0.05:$ non-significant, $\square: P<0.05$ : significant, $\square \square: P<0.01$ : highly significant, SD: standard deviation, $M V$ : mechanical ventilation, WBCs: white blood cells, Hb: hemoglobin

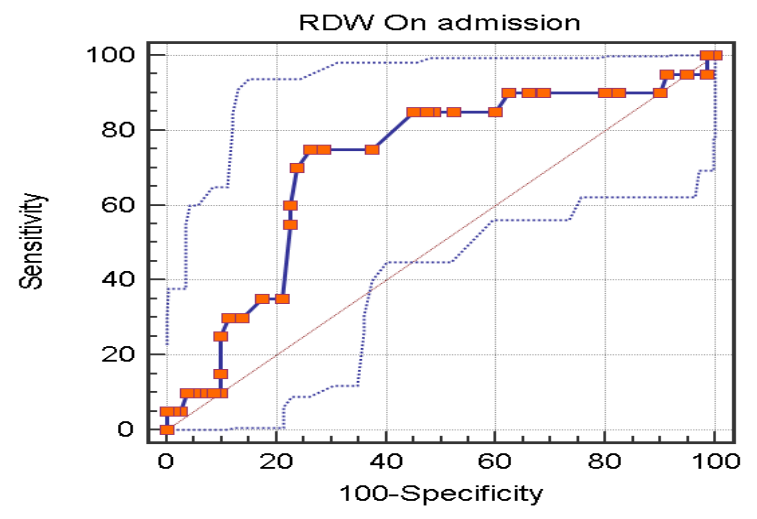

Figure (3): ROC curve of RDW on admission and mortality

\section{Discussion}

Unintentional and suicidal poisoning are the highest burden that face low and middle-income countries. More than $25 \%$ of the global burden of disease is related to environmental factors including exposure and inappropriate use of toxic chemicals (Z'gambo et al., 2016). Organophosphates compounds have biological effects might be harmful as they interact with a lot of enzymes, proteins, transcription factors and receptors (Androutsopoulos et al., 2013). Poisoning with OPCs is the most widely used for suicide with a mortality rate of $10 \%-20 \%$ in spite of the great achievements in ICU management. Therefore, it is important to estimate the severity and prognosis in the early stage of the intoxication (Lee et al., 2013).

The present study was a prospective cross sectional, hospital-based study carried out on 100 patients admitted to PCC-ASUHs of acute organophosphate poisoning (AOPP) who were selected according to predetermined criteria. This work aimed to investigate and assess the prognostic value of red cell distribution width (RDW) which measured on admission and after 24 hours and white blood cells (WBCs), hemoglobin and Platelets which measured on admission to the emergency department on severity and outcome in patients with acute organophosphate poisoning in conjunction with clinical signs using the Peradeniya Organophosphorus Poisoning (POP) score. In addition, evaluating and comparing between RDW with PChE as early OPCs poisoning predictors in patients admitted to PCC-ASUHs.

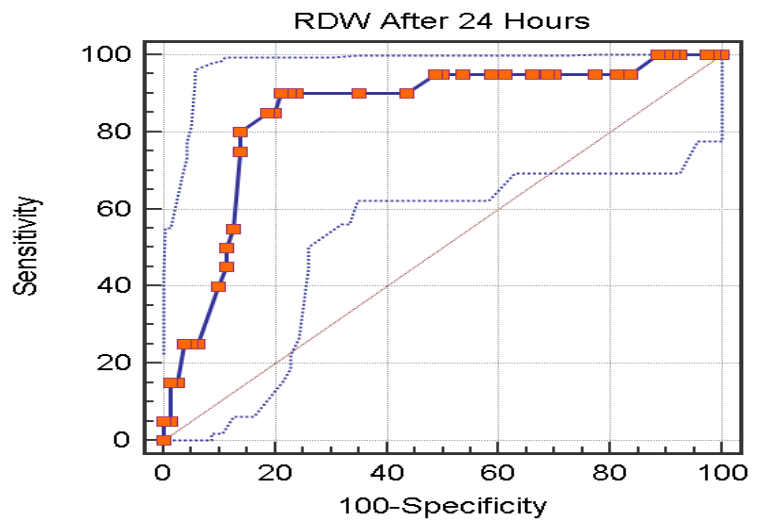

Figure (4): ROC curve of RDW after 24 hours and mortality

Elevated RDW has been suggested to be associated with oxidative stress and systemic inflammation as a result of deformation of erythrocyte membranes, similarly, AOPP is considered a state of acute inflammation and oxidative stress. Hence, RDW levels may be increased in AOPP and as a consequence it can help in prognosis (Shaikh and Vadivelan, 2015).

In the present study, there is a highly significant correlation between RDW values and the need for mechanical ventilation which is in accordance with results of Dündar et al., (2015) who reported that mechanically ventilated patients with OPCs had higher RDW levels on admission to ER. Hypoxia is a main cause of stress induced factors such as stem cell factor and glucocorticoids ,the later stimulate erythropoietin production and interact with c -kit, the receptor of stem cell factor causing attenuation of erythroid progenitors and sustained proliferation of immature red blood cells elevating RDW (Tiffany et al., 2018). Consequently, RDW is a readily obtainable hematological parameter without the need for further cost, we propose that it can be used as a valuable marker of mortality (Hsieh et al., 2017).

In the present study, red cell distribution width on admission could predict the need for mechanical ventilation with sensitivity $(58.97 \%)$ and specificity $(83.61 \%)$ with cutoff point more than $(14.4 \%)$. This is in accordance with the results of Shaikh and Yadavalli, (2017) who reported RDW sensitivity of $57.1 \%$. 
Similarly, Dündar et al., (2015) recorded RDW specificity of $70 \%$ with a similar cutoff point.

Moreover, RDW on admission had a sensitivity of $75 \%$ and specificity of $73.75 \%$ with a cut-off value of more than $14.3 \%$ in predicting mortality in patients with OPCs poisoning. These findings agreed with results of Pranaav and Prabhu, (2019) who recorded a sensitivity of (71.4\%) and specificity (85\%) and with the results of Elhosary and Abd-ElBar., (2018) who reported a cut-off value more than $(14.3 \%)$.

In the present study, after 24 hours RDW reading in predicting mortality of OPCs patients had a sensitivity of (90\%) and specificity of $(78.75 \%)$ with a cut-off value of more than $(14.5 \%)$ which is similar to the study done by Jainy, (2019) who had a cut-off value $(14.05 \%)$ with a sensitivity of $(85.3 \%)$.

In the present study, there was a statistically significant correlation between RDW on admission and outcome as the mean $\pm \mathrm{SD}$ for non-survived and survived patients were $(14.680 \pm 1.422 \%)$ and $(13.786 \pm 1.149 \%)$, respectively this in accordance with Kang et al., (2014) who reported higher RDW values in the deaths more than the survivors. So higher RDW values indicate poor prognosis and the need for mechanical ventilatory support, and this agreed with results of a study done by Jainy, (2019) who recorded nearly similar mean \pm SD for the deaths and the recovered cases $(15.56 \pm 1.57 \%)$ and $(12.86 \pm 1.37 \%)$ respectively.

There is a significant correlation between mechanical ventilation and the poor outcome, and it is similar to the results of Kang et al., (2014) which reported that the need for mechanical ventilation was a significant predictor of a poor outcome. Respiratory compromise and death from AOPP may occur as a consequence of several factors that impair ventilation and oxygenation. Consequently, the combination of the peripheral muscarinic effects of OPCs, paralysis of the respiratory muscle in addition to respiratory center depression may results in poor prognosis (Roberts and Brett, 2014).

There was no significant correlation between initial PChE and the need for mechanical ventilation in the current study. This result coincides with the study done by Kumar et al., (2017) and Yuan et al., (2018) that reported no significant correlation between PChE levels and the need for mechanical ventilation on admission. Thus, from the current study we can conclude that cholinesterase level cannot be used as reliable indicator for the selection of treatment modality nor categorize patients who might need mechanical ventilation on admission. However, Honnakatti et al., (2018) reported significant correlation between serum cholinesterase level and severity of poisoning on presentation.

In our study there is a significant correlation between high WBCs and the severity of the poisoning and the need for mechanical ventilation. This is similar to the results of by Kumar et al., (2018) who reported that the leukocytic count on admission can be used as a prognostic marker of severity of AOPP. Its pathological mechanism could be explained by the strong stress, OPCs stimulate the body to produce a series of stress reaction, promoting the increase of WBC (Yuan et al., 2018)

Moreover, there was no statistically significant difference between groups in accordance with $\mathrm{Hb}$ as the results of Dündar et al., (2015) who explained that normal $\mathrm{Hb}$ levels of patients with AOPP on admission were possibly due to the non-depleted antioxidant capacity of erythrocytes early in poisoning.

Additionally, there is no statistically significant difference between platelets and severity of poisoning and this is similar to results of the study by Zhou et al., (2016) as they did not detect statistically significant differences between the severity of poisoning and platelets count, in contrast study by Tang et al., (2018) and Jainy., (2019) who found significant correlation between platelets and severity of poisoning.

In our study, there is a highly significant correlation between RDW values on admission and the need for mechanical ventilation but, there was no significant correlation between PChE on admission and the need for mechanical ventilation. Hence, from the current study we can conclude that RDW levels measured on admission to the ED can be used as a prognostic marker in patients with AOPP (Dündar et al., 2015).

Pseudo cholinesterase level changes cannot reflect the extent of clinical intoxication and should not be used as the solitary reference when diagnose and estimating the severity of AOPP (Tang et al., 2018). Thus, as a conclusion PChE level cannot be used as reliable indicator for categorizing patients according to their need to mechanical ventilation on admission (Kumar et al., 2017).

\section{Conclusion}

In conclusion, since complete blood count including (RDW and WBCs) are most commonly used tests in emergency department patients in contrast to PChE levels which is not obtainable in every healthcare facility. RDW could assist as an easy-to-obtain markers for severity of acute organophosphate poisoning. There is a significant correlation between RDW values and WBCs. There is a highly significant correlation between the need for mechanical ventilation and RDW values and POP score. Furthermore, there was a nonsignificant correlation between serum PChE levels and severity. Additionally, there was a significant correlation between WBCs with the need of mechanical ventilation. RDW is a predictor of severity of acute organophosphate poisoning with a sensitivity $(58.97 \%)$, specificity $(83.61 \%)$ on admission and with a sensitivity (61.54\%), specificity (86.89\%) after 24 hours Additionally, RDW on admission had a sensitivity of $75 \%$ and specificity of $73.75 \%$ with a cut-off value of 14.3 in predicting mortality in patients with OPCs poisoning.

\section{Recommendations}

- The health authorities worldwide should encourage limited usage of OPCs for its targeting purposes only and sharing the awareness about their hazardous affection on health of the human and 
environment. Additionally, encouraging researchers to find newer and safer OPCs to the sake of the human and the community.

- Awareness about the opinion of all religions about suicidal attempts.

- Early recognition and assessment of AOPP using POP score would help in rapid management, preventing sequalae and improving the outcome.

- Red Cell distribution Width could be considered a tool for prognosis and evaluation for the severity and outcome for AOPP patients.

- Further studies on a larger scale may be needed to confirm and validate our markers as a prognostic marker.

\section{References}

Androutsopoulos V. P, Hernandez A. F, Liesivuori J, et al., (2013): A mechanistic overview of health associated effects of low levels of organochlorine and organophosphorus pesticides. Toxicology; 307: 89-94.

Cestonaro L.V, Garcia S.C, Nascimento S, et al., (2020): Biochemical, hematological and immunological parameters and relationship with occupational exposure to pesticides and metals. Environmental Science and Pollution Research.; 27:29291-29302.

Chaudhary S and Kalmegh R (2018): Study of role of prognostic markers in the management of organophosphorus poisoning patients. International Journal of Research in Medical Sciences; 6 (6):1996-1999.

Dündar Z.D, Köylü R, Ergin M, et al., (2015): Prognostic value of red cell distribution width in patients with organophosphate poisoning. The journal of academic emergency medicine; 14 : 6569.

Elhosary N.M and Abd-ElBar E.S (2018): Red cell distribution width, neutrophil lymphocyte and platelet lymphocyte ratios as prognostic markers in acutely pesticides poisoned patients. Egypt J. Forensic Sci. Appli. Toxicol;18(4):29-40.

Honnakatti V, Nimbal N and Doddapattar P (2018): A study on serum cholinesterase level in organophosphorus poisoning and its correlation with severity of organophosphorus poisoning. Int J Adv Med;5(4):1021-1025.

Hsieh Y.P, Tsai S.M, Chang C.C, et al., (2017): Association between red cell distribution width and mortality in patients undergoing continuous ambulatory peritoneal dialysis. Scientific Reports, 7(1).

Jainy J (2019): Red cell distribution width as a prognostic marker in acute organophosphorus poisoning, Madras Medical College, Chennai.175.

Kang C, In Park S, HoonKim D, et al., (2014): Red cell distribution width as a predictor of mortality in organophosphate insecticide poisoning. American Journal of Emergency Medicine; 32(7):743-746.
King A.M and Aaron C.K (2015): Organophosphate and carbamate poisoning. Emerg Med Clincs of North America;33(1): 133-151.

Kumar A, Margekar S.L, Margekar P et al., (2018): Recent advances in management of organophosphate \& carbamate poisoning. Indian Journal of Medical Specialities; 9(3): 154-159.

Kumar G.R, Rao PSV.R and Nrushen P (2017): A study on serum cholinesterase levels as a prognostic marker in organophosphorus poisoning. Asian Pac. J. Health Sci; 4(1):91-99.

Lee J.H, Lee Y.H, Park Y.H, et al., (2013): The difference in C-reactive protein value between initial and 24 hours follow-up (D-CRP) data as a predictor of mortality in organophosphate poisoned patients. Clinical Toxicology; 51(1): 29-34.

Peter J.V,Sudarsan T.I and Moran L.J(2014):Clinical features of organophosphorous poisoning: A review of different classification systems and approaches. Indian Journal of Critical Care Medicine. 02014 Nov; 18(11):735-745.

Pranaav S.A and Prabhu A (2019): Red cell distribution width as outcome predictor in organophosphate poisoning. IOSR Journal of Dental and Medical Sciences (IOSR-JDMS): 18(8):26-29.

Roberts D and Brett J (2014): Clinical management of acute OP pesticide poisoning, Balali-Mood M and Abdollahi $\mathrm{M}$ (editors), basic and clinical toxicology of organophosphorus compounds. () Springer-Verlag London; chapter 6: 141-76.

Sapkota S, Khanal A, Maskey A, et al., (2018): Study of leukocytes level as a prognostic marker in patients with organophosphate poisoning. Journal of Advances in Internal Medicine; 06(01): 6-10.

Shaikh M.A and Vadivelan A.A (2015): Red cell distribution width as prognostic marker in organophosphorous compound poisoning. IOSR Journal of Dental and Medical Sciences: 14(9): 21-24.

Shaikh M.A and Yadavalli (2017): Red cell distribution width as a prognostic marker in severe sepsis and septic shock. International Journal of Advances in Medicine; 4(3):750-754.

Tiffany M.N, Otero D, Dante Y, et al.,(2018):Elevated red cell distribution width is associated with decreased ventilator-free days in critically ill patients. Journal of intensive care medicine, 33(4)241-247

Tang Y, Hu L, Hong G, et al., (2018): Diagnostic value of complete blood count in paraquat and organophosphorous poisoning patients. Toxicology and Industrial Health, 34(7): 439-447

Vernekar P.V and Shivaraj K (2017): Peradeniya organophosphorus poisoning scale (POP) as a predictor of respiratory failure and mortality in organophosphorus poisoning. Scholars Journal of Applied Medical Sciences; 5(5B):1841-1844.

Yuan SH, Gao Y, Wenqing Ji, et al., (2018): The evaluation of acute physiology and chronic health evaluation II score, poisoning severity 
score, sequential organ failure assessment score combine with lactate to assess the prognosis of the patients with acute organophosphate pesticide poisoning. Medicine (Baltimore); 97(21): e10862.

Z'gambo J, Siulapwa Y and Michelo C (2016): Pattern of acute poisoning at two urban referral hospitals in Lusaka, Zambia. BMC Emergency Medicine, 16(2):1-8.
Zhou D.C, Zhang H, Luo Z.M, et al., (2016): Prognostic value of hematological parameters in patients with paraquat poisoning. Scientific Reports, 6(1):1-9.

\section{قياس توزيع حجم كرات الام الحمراء ومستوى اللاكتات بالام كمتنبئات لثدة ونتيجة التسمم الحاد بالمبيدات

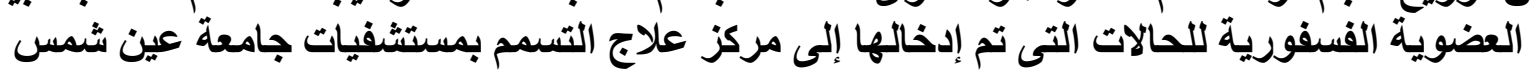

منال السيد عبدالسلام، هبة محمد حلاوة، رباب نبيل حافظ، إهداءعبد الباسط محمود '

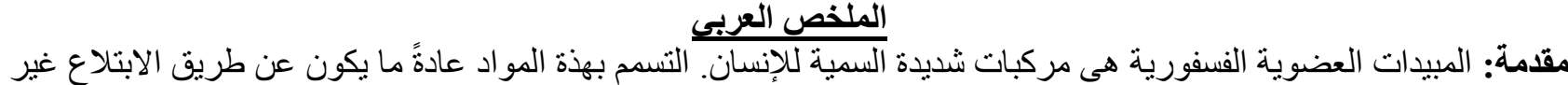

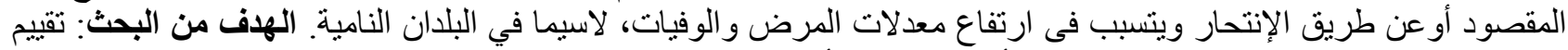

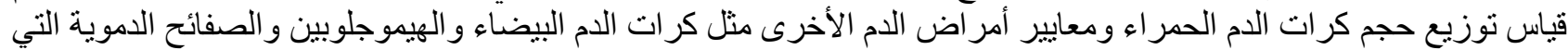

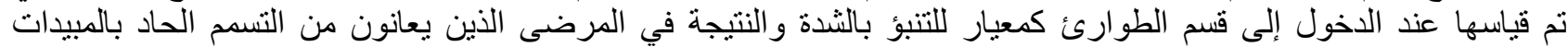

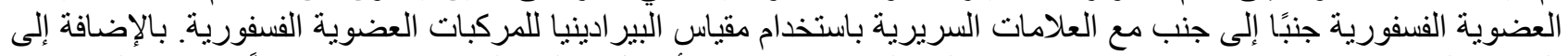

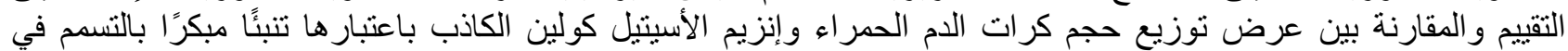

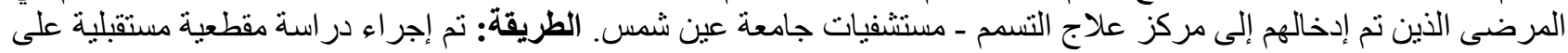

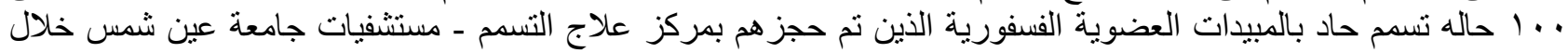

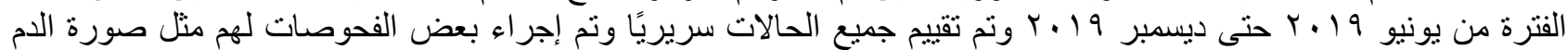

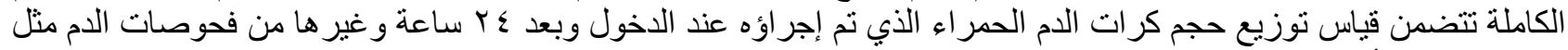

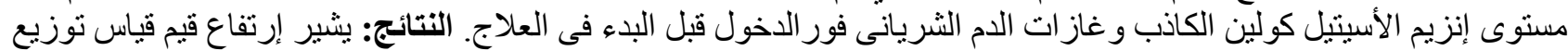

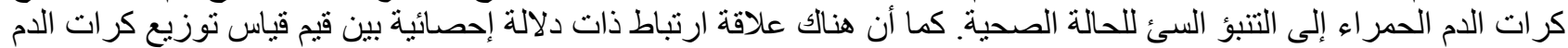

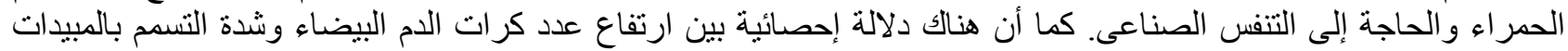

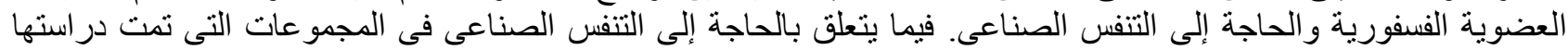

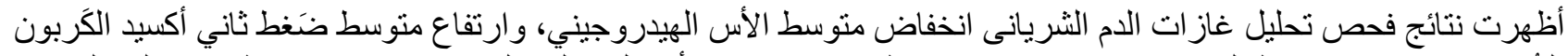

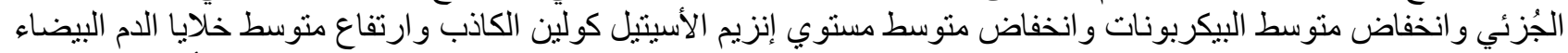

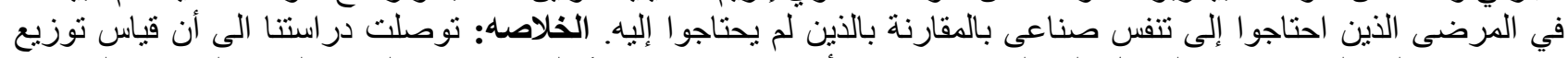

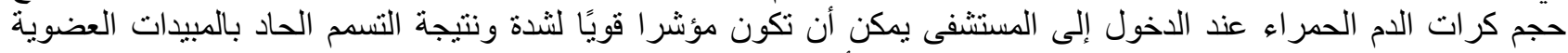

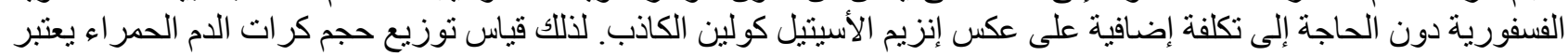

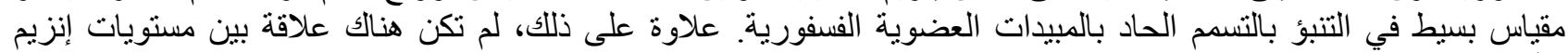

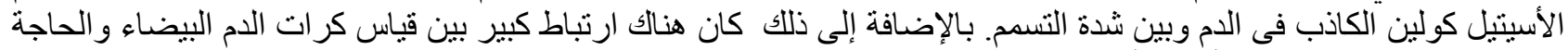

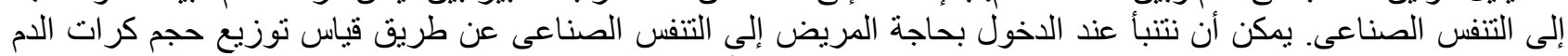

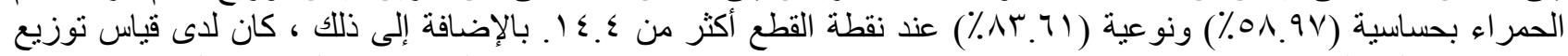

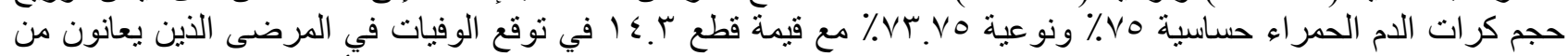

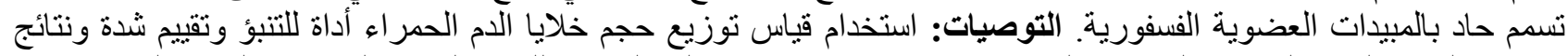

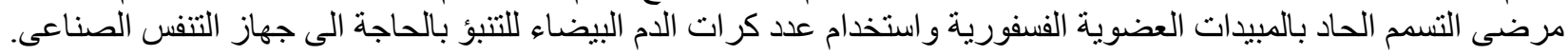

